\title{
Impact of Ambient Temperature on Electricity Demand of Dhaka City of Bangladesh
}

\author{
Arif Istiaque1, Shahidul Islam Khan ${ }^{2 *}$ \\ ${ }^{1}$ Department of Electrical, Electronics \& Communication Engineering, Military Institute of Science and Technology, Mirpur, \\ Dhaka, Bangladesh \\ ${ }^{2}$ Department of Electrical \& Electronics Engineering, BRAC University, Dhaka, Bangladesh \\ Email: *shahidul.khan@bracu.ac.bd
}

How to cite this paper: Istiaque, A. and Khan, S.I. (2018) Impact of Ambient Temperature on Electricity Demand of Dhaka City of Bangladesh. Energy and Power Engineering, 10, 319-331.

https://doi.org/10.4236/epe.2018.107020

Received: April 9, 2018

Accepted: July 6, 2018

Published: July 9, 2018

Copyright $\odot 2018$ by authors and Scientific Research Publishing Inc. This work is licensed under the Creative Commons Attribution International License (CC BY 4.0).

http://creativecommons.org/licenses/by/4.0/

\begin{abstract}
Per capita electricity consumption of Bangladesh is $400 \mathrm{KWh}$. Of the total population of 160 million, only 40 percent has the access of using electricity. Dhaka city consumes about $40-45$ percent of the total electricity generation of the country. This study reports the trend of electricity use in the Dhaka city with emphasis on the impact of changing temperature due to urbanization and weather change. Hourly data of electricity demand of Dhaka city and the temperature profile of the city for a period of thirty months have been used for this study. To relate weather data like temperature, humidity, wind speed, wind direction, atmospheric pressure, dew point and visibility etc. with electricity demand of the city about 16,508 data between 2011 and 2017 have been considered. A statistical regression has been done to establish a relation between them. From this study it is found that reduction of only $1^{\circ} \mathrm{C}$ air temperature could save $81 \mathrm{MV}$ of electricity consumption in Dhaka city. A time series forecast has been done to estimate probable temperature change and subsequent electricity consumption up to year 2020. From the study it has been established that the temperature dependence of electricity consumption in Dhaka city is about $75 \%$.
\end{abstract}

\section{Keywords}

Electricity Consumption, Temperature Rise, Time Series Forecasting, Statistical Regression

\section{Introduction}

Dhaka, the capital of Bangladesh is a densely populated city. It is one of the fastest growing mega cities of the world. Sixteen million people live within the area 
[1] of approximately $415.16 \mathrm{~km}^{2}$. This population increase is mainly due to rural to urban migration. Land covered area within the city creates an urban heat island and expansion of population has been identified as the major contributor of temperature increase and hence the electricity consumption. The aim of this paper is to analyze and clarify the increase in electricity consumption in this city due to temperature increase. Dhaka is a very hot, humid and rusty. Therefore it consumes a significant amount of electricity for cooling purpose. However its population is expanding day to day in a significant number. Thus a proper approximation is needed to find out the electricity demand for next years due to temperature increase.

The electrical energy consumption of a city is closely related to its ambient temperature [2]. Urban temperature is changing because of heat island effect and global warming. The study [3] conducted by Pili-Sihvola found the gradual impact of global warming and climate change using a multivariate regression model for five European countries. The average yearly urban temperature varies from $1^{\circ} \mathrm{C}-3^{\circ} \mathrm{C}$ higher than that of rural areas in hot summer days [4] and in a cold nights it may vary more than $12^{\circ} \mathrm{C}$ for the same area [5] [6].

To examine factors influencing energy consumptions, many studies have been conducted. Some of them [7]-[16] approached the problem from an urban heat island perspective. Parkpoom and Harrison [7] in their work used regression models in Thailand, Engle [8] used semi-parametric estimations, Hor [9] used regression models in Wales and England on a monthly basis, Hyndman and Fan [10] used a semi-parametric additive model and presented the impact of weather variables on electric power demand. The relationship between electricity demand and temperature is not linear. Studies empirically investigated the non-linearity in the relationship using parametric and non-parametric methods as shown by Henley and Peirson [11]. Demand is driven by differences between outdoor and indoor temperature. When difference of outdoor and indoor temperature is significant heating/cooling demand rises. The analysis performed by Terasvirta and Anderson [12] proposes a set of smooth-transition autoregressive models for the evolution from a cold threshold temperature to a warm threshold temperature. Akbari [13] reported that the peak cooling electricity load in some US cities would increase between $0.5 \%$ and $3 \%$ per $0.6^{\circ} \mathrm{C}$ ambient temperature. Santamouris [14] observed that the cooling load of urban buildings in central Athens almost doubles in summer and heating load reduces up to $30 \%-55 \%$ in winter compared to the buildings located in non-suburban areas. Primitive variables included temperature, relative humidity $(\mathrm{RH})$ and wind speed. Derived variables were cold, hot and latent days. In studies conducted by Badr and Nasr [15] of Lebanon used co-integration and error-correction models and Parkpoom [16] in Thailand used a multiple linear regression model and investigated the impact of climate changes on electricity demand. All these studies concluded that the ambient temperature is a primary factor governing the up and down of energy consumption in urban areas. 


\section{Data Collection and Methodology of the Study}

The methodology is empirical and statistical. A multiple linear regression was first carried out to explore the dependence of the monthly consumption of each energy product on meteorological parameters. Five meteorological variables were selected. They are ambient temperature, relative humility (rainfall related), wind speed, wind direction, and precipitation. Pearson's correlation and covariance [17] has been used to establish relation between the variables. The positive value of covariance determines positive relation between two variables and vice versa. Higher the correlation value, better is the relation described. The results shown that temperature accounted about $75 \%$ of the total variance. Therefore, it is assumed that the energy consumption $\mathrm{Y}$ is a function of ambient temperature X. For simplicity, the term "ambient temperature" is denoted by "temperature" in all subsequent sections. The relationship between the monthly electricity consumptions and temperature was explored by plotting the hourly electricity consumption against the hourly mean temperature. When the electricity consumption appeared temperature dependent, the function for the electricity was constructed using a least-square regression analysis (Figures 5-8). Four types of functions were tested, they include linear $(y=A x+B)$ in Figure 5, Bilinear $\left(y=A x^{2}+B x+C\right)$ in Figure 6, logarithmic $(y=A \ln (x)+B)$ in Figure 7 , and exponential $\left(y=A e^{D x}\right)$ in Figure 8 , where, $A, B, C$ and $D$ are constants. The best fit was selected using the smallest $p$-value* and the largest coefficient of determination $\mathrm{R}^{2 *}$. As this study followed an empirical and statistical way, the multiple linear regression technique is one of the best fit options for making a relationship between the variables. This technique may not be appropriate due to the level of variable measurement or multicollinearity. As the paper avoided multicollinearity for complexity the above mentioned functions are enough for finding the best fit. The function then allows $\mathrm{Y}$ to be modelled at different temperatures.

Taking electricity demand as a function of temperature, the demand can be calculated as

$$
Y(\text { hour, } x)=m \mathrm{e}^{D . x}
$$

For every $1^{\circ} \mathrm{C}$ rise of temperature the electricity demand would be

$$
Y(\text { hour }, x+1)=m \cdot \mathrm{e}^{D \cdot(x+1)}
$$

The demand reduction due to decrase of $1^{\circ} \mathrm{C}$ of weather temperature would be

$$
\Delta Y=Y(\text { hour, } x+1)-Y(\text { hour, } x)
$$

Real time hourly data of ambient temperature form year 2011 to year 2017 has been collected from Bangladesh Meteorological Department. Using these values a time series analysis has been done to estimate probable temperature situation up to year 2020 (Table 1). Using time series analysis for electricity consumption and regression equation, a probable electricity consumption forecasting has been carried out for temperature change. As electricity demand does not depend on temperature variables alone, control variables should also include variables like 
Table 1. Forecasted values of mean monthly maximum temperature.

\begin{tabular}{|c|c|c|c|c|c|c|c|c|c|c|c|c|c|}
\hline \multirow{2}{*}{ Year } & \multicolumn{12}{|c|}{ Mean monthly maximum temperature $\left({ }^{\circ} \mathrm{C}\right)$} & \multirow[t]{2}{*}{$\begin{array}{l}\text { Yearly } \\
\text { average }\end{array}$} \\
\hline & Jan & Feb & Mar & Apr & May & Jun & Jul & Aug & Sep & Oct & Nov & Dec & \\
\hline 2011 & 20.5 & 25.5 & 28.5 & 30.5 & 31 & 30 & 29.5 & 29 & 29 & 29.5 & 26 & 23.5 & 27.71 \\
\hline 2012 & 21 & 25.5 & 28.5 & 30.5 & 32.5 & 31.5 & 30 & 29 & 29 & 28 & 25 & 21 & 27.63 \\
\hline 2013 & 22 & 26 & 30 & 32 & 30.5 & 31 & 30 & 29.5 & 30 & 28 & 27 & 24.5 & 28.38 \\
\hline 2014 & 23.5 & 26 & 30 & 33.5 & 34 & 32.5 & 31 & 30 & 30.5 & 29 & 28.5 & 24.5 & 29.42 \\
\hline 2015 & 24 & 26.5 & 30 & 33 & 33 & 32 & 30 & 30.5 & 32 & 29.5 & 28 & 25 & 29.46 \\
\hline 2016 & 25 & 27.5 & 31 & 34 & 33.5 & 32 & 31 & 31 & 31 & 30.5 & 27.5 & 26 & 30 \\
\hline 2017 & 25.3 & 27.8 & 31.3 & 34.3 & 33.8 & 32.3 & 31.3 & 31.3 & 31.3 & 30.8 & 27.8 & 26.3 & 30.3 \\
\hline 2018 & 25.7 & 28.2 & 31.7 & 34.7 & 34.2 & 32.7 & 31.7 & 31.7 & 31.7 & 31.2 & 28.2 & 26.7 & 30.7 \\
\hline 2019 & 26.2 & 28.7 & 32.2 & 35.2 & 34.7 & 33.2 & 32.2 & 32.2 & 32.2 & 31.7 & 28.7 & 27.2 & 31.2 \\
\hline 2020 & 26.7 & 29.2 & 32.7 & 35.7 & 35.2 & 33.7 & 32.7 & 32.7 & 32.7 & 32.2 & 29.2 & 27.7 & 31.7 \\
\hline $\begin{array}{l}\text { Monthly } \\
\text { average }\end{array}$ & 23.9 & 27.09 & 30.59 & 33.34 & 33.24 & 32.09 & 30.94 & 30.69 & 30.94 & 30.04 & 27.59 & 25.24 & \\
\hline
\end{tabular}

GDP growth, population, increase of cooling appliances and price per unit of electricity. Due to lack of data at regional level, the effect of time-varying variables has been neglected. Lastly the study does not include other effects of climate change which might indirectly influence electricity demand, such as changes in wealth and energy efficiency, new technologies etc.

\section{Analysis, Result and Discussion}

Bangladesh has electricity production capacity of 15,761 MW (Source: Power Grid Company of Bangladesh Limited, PGCBL). BPDB has taken a massive capacity expansion plan to add about 11,600 MW generation capacity in next 5 years to achieve $24,000 \mathrm{MW}$ capacity with the aim to provide quality and reliable electricity to all Bangladeshi people. The power system is being expanded to keep pace with the fast growing demand, he added. Sources said the number of power connection receivers in Bangladesh have risen to some 26 million so far year 2017. Despite a robust rise in the capacity, the official who declined to be named, said the current power generation is, to some extent, insufficient to meet increasing demand. The total power production of Bangladesh varies within 10,000 - 13,000 MW (including captive) in hot summer days, and 7000 - 8500 MW in winter days. Dhaka city consumes 4000 - 4500 MW electricity alone, which is about 40 percent of the total. Figure 1 shows the demand curve of a hot sunny day (July 1, 2017). Figure 2 compares the monthly consumption of Dhaka city to total electricity consumption for the year 2016.

Weather condition plays a vital role in electricity demand all over the world. As Bangladesh is a hot, humid and moist country, ambient temperature is vital issue for power demand.

Figure 3 and Figure 4 show the change of electricity demand with respect to temperature for 47 months (Jan, 2014-July, 2017). The data reveals that temper- 
ature controls electricity demand except some aberration. Total 16,508 numbers of temperature sample and corresponding hourly electricity demand data has been selected for this analysis. Every one hour temperature and demand data has been taken while for extreme load shedding and city black out some data has been neglected.

In general, power consumption increases when temperature rises in Dhaka city. This is also true for Bangladesh as a whole. The following curve fitting figures (Figures 5-8) revealed that the temperature and demand are highly inter-related.

Tables 2-5 show the Pearson's correlation and covariance result between two variables.

As shown in Figure 8, the exponential fitting has the highest $r$ squared value and lowest $\mathrm{p}$ value which supports the best relation between temperature and

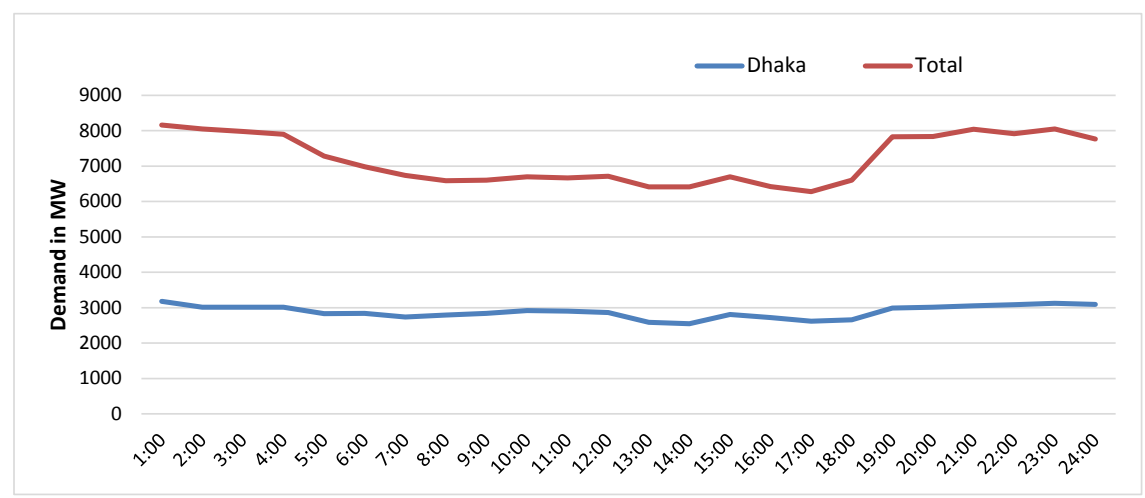

Figure 1. Daily demand curve of on 1 July 2017 [source: PGCBL].

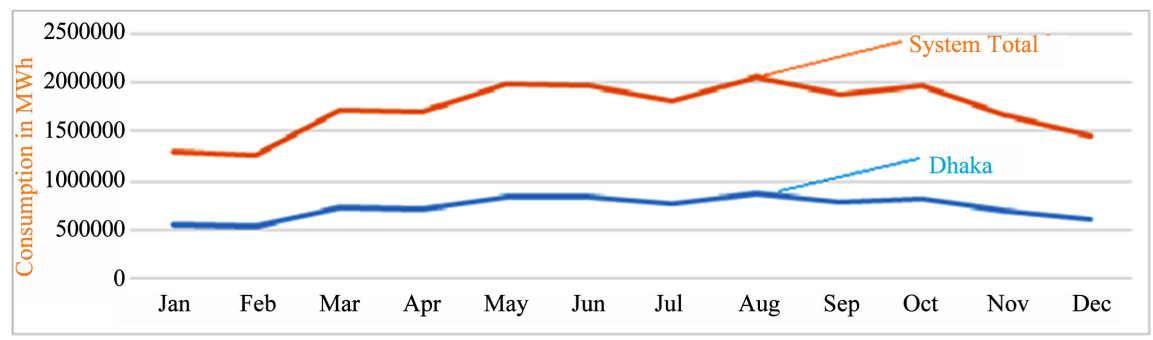

Figure 2. Monthly energy consumption of the year 2016 [source: PGCBL].

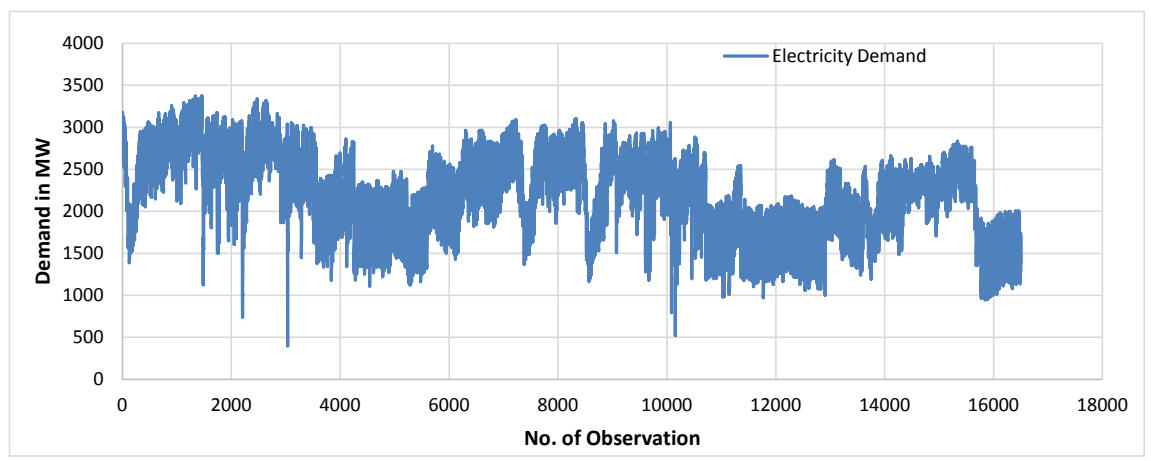

Figure 3. Electricity demand of Dhaka city of 47 months (January 2014-July 2017) [Source: PGCBL]. 


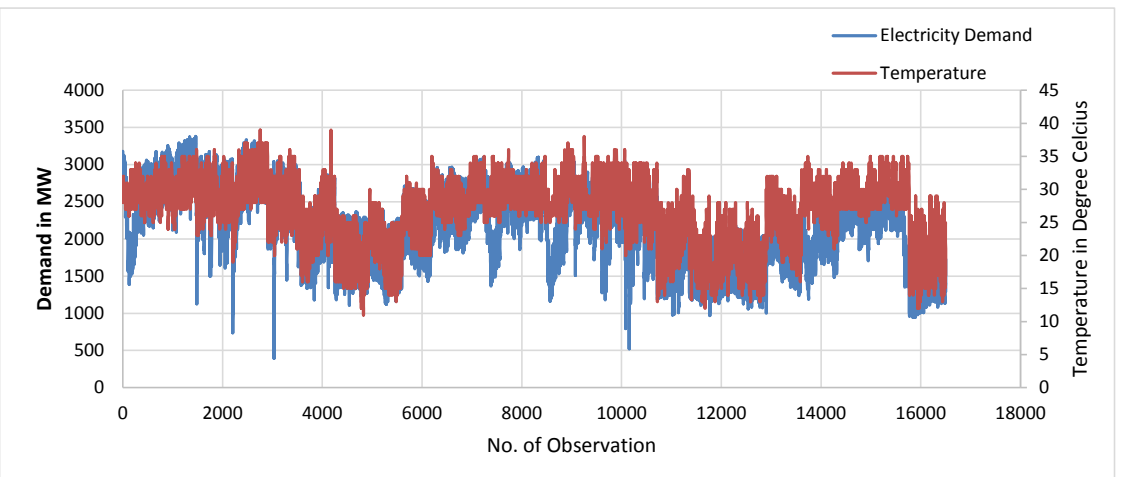

Figure 4. Demand vs. Temperature Curve of Dhaka city of 47 months (January 2014-July 2017).

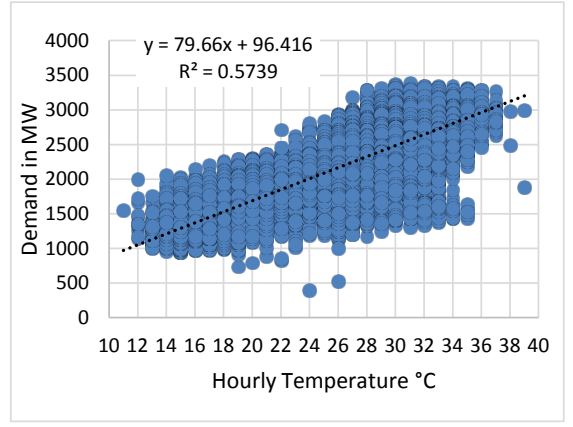

Figure 5. Linear curve fitting between electricity demand and ambient temperature.

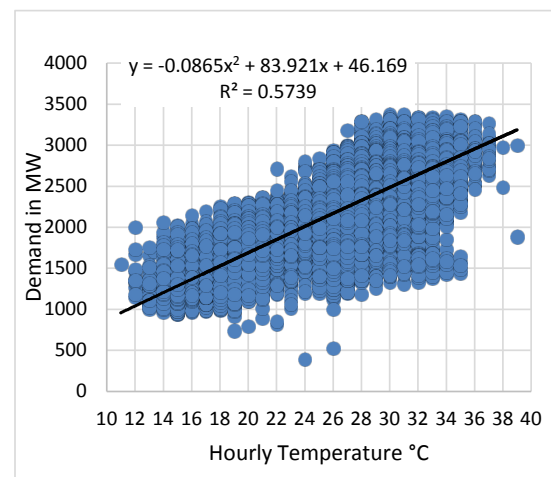

Figure 6. Bilinear curve fitting between electricity demand and ambient temperature.

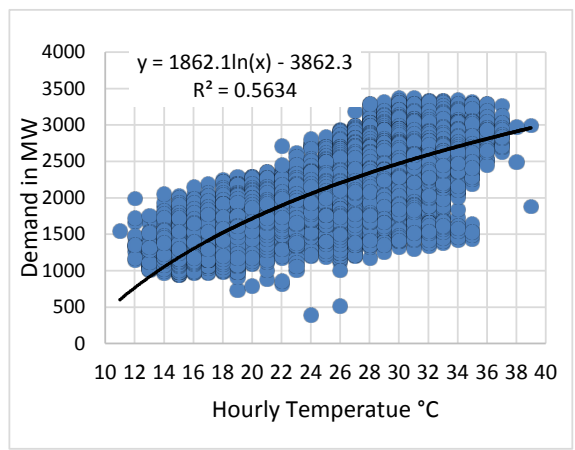

Figure 7. Logarithmic curve fitting between electricity demand and temperature. 


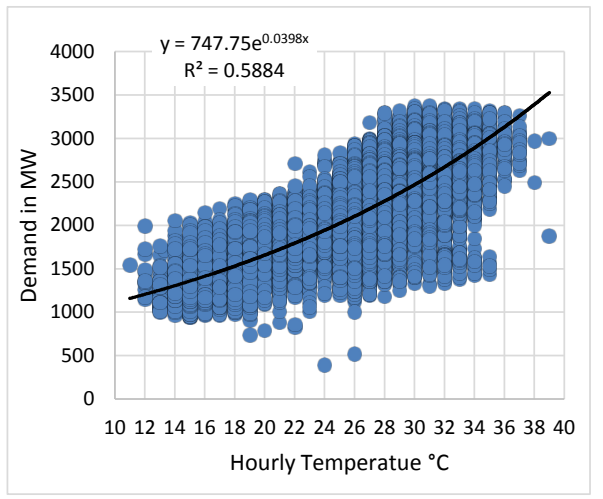

Figure 8. Exponential curve fitting between electricity demand and temperature.

electricity demand, the overall prediction equation for electricity consumption on a single hour can be shown by following equation.

$$
y=747.75 \mathrm{e}^{0.0398 x}
$$

where, $X$ is the mean monthly maximum temperature and $\mathrm{Y}$ is the electricity demand of the Dhaka city. Being the best curve fitted model Equation (4) has been used for peak power demand computation corresponding to threshold temperatures and depicted in Table 5. The correlation between electricity demand and mean monthly maximum temperature is not the best fit for every month. It implies that there are other factors account to increase in the electricity demand e.g. population, increased rate of cooling appliances, unit price of electricity, etc. In this paper attempt has been made to calculate the expected change in electricity demand, due to the increase of mean monthly maximum temperature for Dhaka city by using the following records of temperatures from January 2011 to December 2017 and therefore using regression analysis a forecasted values of temperature assumed upto December 2020 (Table 1). Figure 9 shows the values of mean monthly maximum temperature series for Dhaka city from January 2011 to December 2020.

Using Equation (4) for corresponding threshold temperatures, electricity demand computed. Table 5 shows the monthly forecasted values of electricity demand which have found using Equation (4) and Figure 10 is the graphical representation of the data.

Dhaka city electricity load is highly seasonal variation dependent. Load peak in the summer is almost two times higher than the winter. However, we can divide Dhaka city in two different parts to show weather fluctuations, warm period (March to October) and cold and moderate period (November to February). Cooling load is the most effective factor in using electricity and load peak in network with the use of cooling devises in warm period. In this paper, the effects of temperature changes on electricity demand and load variations are studied. In the study load variation index and temperature correlation coefficient are calculated.

The temperature rise in Dhaka city is most prominent in the months of March, April and May. In March the temperature is between $26^{\circ} \mathrm{C}-32^{\circ} \mathrm{C}$ with a 
Table 2. Covariance ${ }^{\#}$ and Pearson's correlation.

\begin{tabular}{ccccc}
\hline & \multicolumn{2}{c}{ Covariance } & \multicolumn{2}{c}{ Pearson's correlation } \\
\cline { 2 - 5 } & Temperature & Electricity Demand & Temperature & Electricity Demand \\
\hline Temperature & 23.46949 & & 1 & 1 \\
Electricity Demand & 1869.588 & 259463.5 & 0.757578 & 1 \\
\hline
\end{tabular}

Table 3. Regression statistics [coefficients of variables $(m$ and $D)$, coefficient of determination $\left(R^{2}\right)$ and significance level (p-value)] for individual month.

\begin{tabular}{|c|c|c|c|c|}
\hline Month & Equation & Constant (m) & $R$ square value & $P$ value \\
\hline January & $\mathrm{y}=938.33 \mathrm{e}^{0.0315 \mathrm{x}}$ & 938.33 & $\mathrm{R}^{2}=0.3306$ & 0.00 \\
\hline February & $\mathrm{y}=888.41 \mathrm{e}^{0.0336 \mathrm{x}}$ & 888.41 & $\mathrm{R}^{2}=0.4475$ & 0.00 \\
\hline March & $\mathrm{y}=1057.8 \mathrm{e}^{0.0298 \mathrm{x}}$ & 1057.8 & $\mathrm{R}^{2}=0.4718$ & 0.00 \\
\hline April & $y=1604.5 e^{0.0177 x}$ & 1604.5 & $\mathrm{R}^{2}=0.3754$ & 0.00 \\
\hline May & $\mathrm{y}=1029.8 \mathrm{e}^{0.0314 \mathrm{x}}$ & 1029.8 & $\mathrm{R}^{2}=0.3409$ & 0.00 \\
\hline June & $y=1606.4 e^{0.02 x}$ & 1606.4 & $\mathrm{R}^{2}=0.2821$ & 0.00 \\
\hline July & $\mathrm{y}=326.03 \mathrm{e}^{0.0666 \mathrm{x}}$ & 1455.2 & $\mathrm{R}^{2}=0.3689$ & 0.00 \\
\hline August & $y=1349.2 e^{0.0377 x}$ & 1349.2 & $\mathrm{R}^{2}=0.3352$ & 0.00 \\
\hline September & $y=1513.6 e^{0.0152 x}$ & 1513.6 & $\mathrm{R}^{2}=0.5032$ & 0.00 \\
\hline October & $\mathrm{y}=1035.4 \mathrm{e}^{0.0296 \mathrm{x}}$ & 1035.4 & $\mathrm{R}^{2}=0.2995$ & 0.00 \\
\hline November & $\mathrm{y}=775.56 \mathrm{e}^{0.0385 \mathrm{x}}$ & 775.56 & $\mathrm{R}^{2}=0.4594$ & 0.00 \\
\hline December & $\mathrm{y}=840.88 \mathrm{e}^{0.0345 \mathrm{x}}$ & 840.88 & $\mathrm{R}^{2}=0.4428$ & 0.00 \\
\hline Overall & $\mathrm{y}=747.75 \mathrm{e}^{0.0398 \mathrm{x}}$ & 747.75 & $\mathrm{R}^{2}=0.5884$ & 0.00 \\
\hline
\end{tabular}

Table 4. Monthly correlation coefficients in a year.

\begin{tabular}{cccc}
\hline Month & Correlation coefficient & Month & Correlation coefficient \\
\hline January & 0.565750467 & July & 0.631738 \\
February & 0.663254 & August & 0.578586577 \\
March & 0.690076 & September & 0.514007602 \\
April & 0.698475353 & October & 0.542152313 \\
May & 0.602025785 & November & 0.666151055 \\
June & 0.531974368 & December & 0.652583771 \\
Overall & & & 0.7575781 \\
\hline
\end{tabular}

Table 5. Monthly forecasted values of electricity demand.

\begin{tabular}{|c|c|c|c|c|c|c|c|c|c|c|c|c|}
\hline \multirow{2}{*}{ Year } & \multicolumn{12}{|c|}{ Electricity consumption (MWh) } \\
\hline & Jan & Feb & Mar & Apr & May & Jun & Jul & Aug & Sep & Oct & Nov & Dec \\
\hline 2014 & 1209,361 & 1173,555 & 1571,965 & 2042,366 & 2152,864 & 1984,005 & 1840,256 & 1785,349 & 1796,106 & 1644,389 & 1476,123 & 1351,784 \\
\hline 2015 & 1296,571 & 1265,158 & 1721,913 & 1707,700 & 1988,717 & 1975,042 & 1812,046 & 2055,334 & 1872,785 & 1958,733 & 1660,048 & 1461,365 \\
\hline 2016 & 1451,450 & 1563,573 & 1970,286 & 2130,994 & 2055,241 & 2281,348 & 1991,819 & 1991,830 & 1848,934 & 2072,920 & 1608,511 & 1565,803 \\
\hline
\end{tabular}


Continued

\begin{tabular}{lllllllllllll}
2017 & 1522,782 & 1519,310 & 1933,514 & 2108,442 & 2135,795 & 1947,116 & 1933,514 & 1933,514 & 1871,142 & 1895,417 & 1627,832 & 1584,611 \\
2018 & 1547,219 & 1543,691 & 1964,542 & 2142,277 & 2170,069 & 1939,382 & 1964,542 & 1964,542 & 1901,170 & 1925,834 & 1653,955 & 1610,040 \\
2019 & 1578,317 & 1574,718 & 2004,028 & 2185,336 & 2213,686 & 2018,125 & 2004,028 & 2004,028 & 1939,381 & 1964,542 & 1687,198 & 1925,834 \\
2020 & 1610,040 & 1630,958 & 2044,307 & 2229,259 & 2258,180 & 2058,689 & 2044,307 & 2044,307 & 1978,362 & 2004,028 & 1721,109 & 1675,412 \\
\hline
\end{tabular}

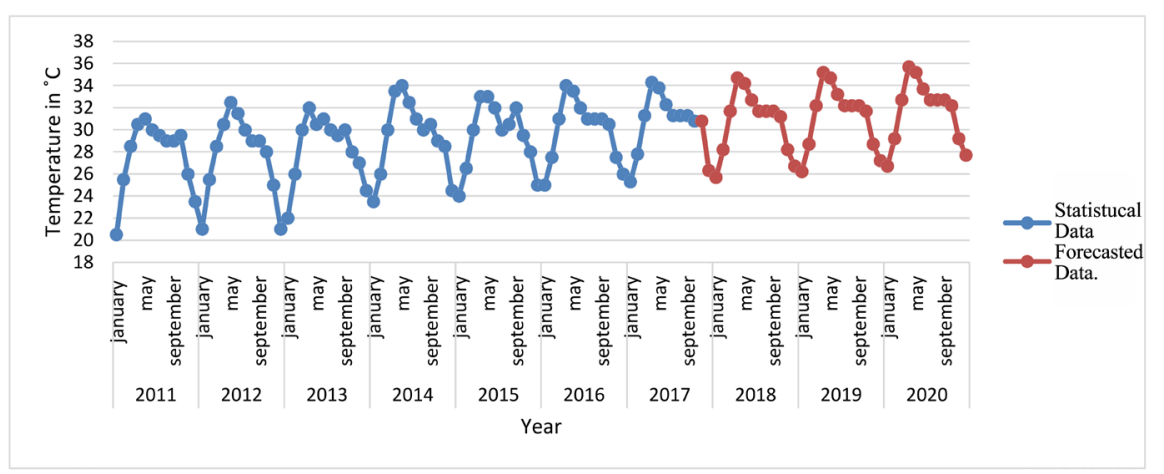

Figure 9. Values of mean monthly maximum temperature series for Dhaka city from Jan, 2011 to Dec, 2020.

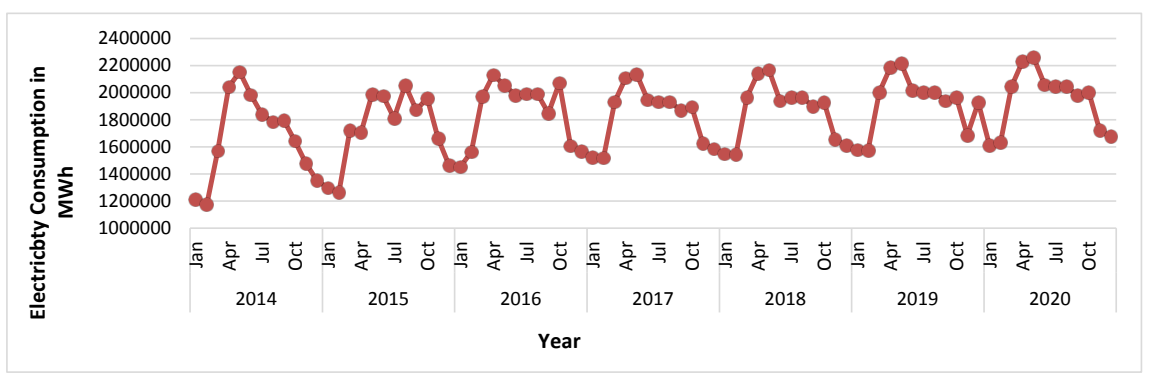

Figure 10. Monthly electricity consumption from Jan, 2014 to Dec, 2020 for Dhaka city.

mean of $30^{\circ} \mathrm{C}$. Correlation coefficient during this month is 0.690076 (Table 4). The average air temperature increases from $26^{\circ} \mathrm{C}$ in February to $30^{\circ} \mathrm{C}$ in May. During this period due to use of air conditioner by consumers, electricity network load remains very high.

During June, the average temperature increases. Due to rainy season precipitation level is high as the humidity is high during the month of June. Humidity is inversely proportional to electricity demand and the correlation coefficient is lowest between the variables. Despite of poor R square value, correlation coefficient supports the relation between electricity demand and temperature. Same is true for the month of October.

The average temperature of Dhaka city increases during July and August without significant increase in the electricity network load. The reason is high precipitation. Correlation coefficient are 0.631738 and 0.578586577 during the months of July and August respectively while R square value is only 0.2089 and 0.3352. Warm period ends during September and October and the average temperature falls. Correlation coefficient are 0.5140067 and 0.542152313 during the 
months of September and October.

Cold period of the year starts in Dhaka from early November. Change in the temperature level occurs from $26^{\circ} \mathrm{C}$ to $18^{\circ} \mathrm{C}$ and it starts moderate weather conditions all over Dhaka city. Excess load which was caused by using electricity for cooling systems reduces during this period. Mild weather conditions reduce electricity network load amount. Regression equation shows a decrease of electricity consumption in the months of November, December, January and February.

From regression analysis shown in Figures 5-8, Equation (4) (Figure 8), the best fit curve for Dhaka city is found as

$$
y=747.75 \mathrm{e}^{0.0398 x}
$$

Change in $1^{\circ} \mathrm{C}$ temperature changes the power consumption (MW) as calculated by Equation (3)

$$
\begin{gathered}
\Delta Y=Y(\text { hour, } x+1)-Y(\text { hour, } x) . \\
\Delta Y=747.75 \mathrm{e}^{0.0398(x+1)}-747.75 \mathrm{e}^{0.0398 x}
\end{gathered}
$$

If temperature decreases from $30^{\circ}$ to $29^{\circ}$ Celsius energy saving for an individual hour would be

$$
\Delta Y=747.75 \mathrm{e}^{0.0398 * 30}-747.75 \mathrm{e}^{0.0398 * 29}=96.28825 \mathrm{MW}
$$

After finding the power change for different range of temperature, it is found that average change in power is about $81 \mathrm{MW}$ for $1^{\circ}$ change in temperature. Change of the air temperature is the reason of load dependence on environment temperature and causes a increase on network load. An overall correlation coefficient between load and temperature has been found to be 0.7575781 during this study.

\section{Conclusion and Discussion}

There is a strong relationship between changes in the temperature and electricity consumption. Based on the data of power consumption for a last 47 months of the City of Dhaka in Bangladesh, it can be concluded that electricity consumption changes in response to change in the mean daily air temperature. The peak electricity consumption is significantly increased during summer season as compared to winter season due to the uses of cooling appliances. This paper forecasts that the mean air temperature of Dhaka city will be increased 2 - 3 degree celsius on an average during next couple of years. This study proved that reduction of $1^{\circ} \mathrm{C}$ air temperature reduces about $81 \mathrm{MW}$ electricity demand of Dhaka city. The forecasted values of monthly electricity demand depicts that electricity consumption is more in hot summer season and highest consumption would be 2258.180 (GWh) in May, 2020 due to increase in temperature. The average monthly behavior of forecast values of temperature and electricity reveals that the maximum temperature has a great influence on electricity consumption keeping other parameters constant. 
The study excludes the discussion of different micro and macroeconomic factors which highly controls the electricity changes behavior. Different analysis could be done to estimate a cross temperature response function, which can represent the effect of non-climate variables on electricity demand at different temperatures. A conventional top-down approach could be followed which needs a thorough and accurate database including a detailed breakdown of appliance categories, their numbers at different years and their power rating at different temperatures. The effect of relative price of electricity per KWh analysis could be significant for heating demand. Moreover, technical progress in electric appliances and changes in consumption habits (proxied by the time trend) analysis would find some more accurate result. Combination of climate and non-climate factors can represent a better estimation.

However, temperature change is not the only factor of the electricity demand change. As stated earlier electricity demand changes with humidity, dew points, wind speed, wind direction and other macro and micro economic factors like GDP growth, population, increase of cooling appliances, price per unit of electricity, ease to access electricity connections in different area etc. However, overall Bangladesh contains high humidity throughout the year. It remains $85 \%$ to 95\% throughout the year. Moreover, climate variables are more or less interrelated to each other. Thus a 360 degree analysis could find a better result. This will need a three dimensional graphical representation to find the relationship between all the climate and non-climate variables and electricity demand changes. To avoid the higher order complexity this paper avoided the other variables which also have a significant role in electricity consumption change. Further work will define compiling the other variables we hope.

\section{Acknowledgements}

The kind support from Bangladesh Meteorological Department is highly acknowledged. We also deeply thank Dr. Md. Farid Ahmmed of Power Grid Company of Bangladesh Ltd. (PGCBL) for helping with electricity demand data.

\section{References}

[1] Statistical Yearbook of Bangladesh, 32nd Edition, Bangladesh Bureau of Statistics, Statistics and Informatics Division, Ministry of Planning, Government of the People's Republic of Bangladesh, Dhaka, Bangladesh, August 2013.

[2] Fung, W., Lam, K., Hung, W., Pang, S. and Lee, Y. (2006) Impact of Urban Temperature on Energy Consumption of Hong Kong. Energy, 31, 2623-2637.

https://doi.org/10.1016/j.energy.2005.12.009

[3] Pilli-Sihvola, K., Aatola, P., Ollikainen, M. and Tuomenvirta, H. (2010) Climate Change and Electric Power Consumption-Witnessing Increasing or Decreasing Use and Costs? Energy Policy, 38, 2409-2419.

https://doi.org/10.1016/j.enpol.2009.12.033

[4] Oke, T.R. (1997) Urban Climates and Global Environmental Change. In: Thompson, R.D. and Perry, A., Eds., Applied Climatology: Principles \& Practices, Rout- 
ledge, New York, 273-287.

[5] Oke, T. (1982) The Energetic Basis of the Urban Heat Island. Quarterly Journal of the Royal Meteorological Society, 108, 1-24.

https://doi.org/10.1002/qj.49710845502

[6] Aniello, C., Morgan, K., Busbey, A. and Newland, L. (1995) Mapping Micro-Urban Heat Islands Using LANDSAT TM and a GIS. Computers \& Geosciences, 21, 965-969. https://doi.org/10.1016/0098-3004(95)00033-5

[7] Parkpoom, S. and Harrison, G.P. (2008) Analyzing the Impact of Climate Change on Future Electric Demand in Thailand. IEEE Transactions on Power Systems, 23, 1441-1448. https://doi.org/10.1109/TPWRS.2008.922254

[8] Engle, R.F., Granger, C.W.J., Rice, J. and Weiss, A. (1986) Semiparametric Estimates of the Relation between Weather and Electricity Sales. Journal of the American Statistical Association, 81, 310-320. https://doi.org/10.1080/01621459.1986.10478274

[9] Hor, C.-L., Watson, S.J. and Majithia, S. (2005) Analyzing the Impact of Weather Variables on Monthly Electricity Demand. IEEE Transactions on Power Systems, 20, 2078-2085. https://doi.org/10.1109/TPWRS.2005.857397

[10] Hyndman, R.J. and Fan, S. (2010) Density Forecasting for Long-Term Peak Electricity Demand. IEEE Transactions on Power Systems, 25, 1142-1153. https://doi.org/10.1109/TPWRS.2009.2036017

[11] Henley, A. and Peirson, J. (1997) Non-Linearities in Electricity Demand and Temperature: Parametric versus Non-Parametric Methods. Oxford Bulletin of Economics and Statistics, 59, 149-162. https://doi.org/10.1111/1468-0084.00054

[12] Terasvirta, T. and Anderson, H.M. (1992) Characterising Nonlinearities in Business Cycles Using Smooth Transition Autoregressive Models. Journal of Applied Econometrics, 7, 119-136. https://doi.org/10.1002/jae.3950070509

[13] Akbari, H., Davis, S., Dorsano, S., Huang, J. and Winert, S. (1992) Cooling Our Communities-A Guidebook on Tree Planting and Light Color Surfacing. US Environmental Protection Agency, Office of Policy Analysis: Climate change Division.

[14] Santamouris, M., Papanikolaou, N., Livada, I., Koronakis, I., Georgakis, C., Argirous, A., et al. (2001) On the Impact of Urban Climate on the Energy Consumption of Buildings. Solar Energy, 70, 201-216. https://doi.org/10.1016/S0038-092X(00)00095-5

[15] Badr, E.A. and Nasr, G.E. (2001) On the Relationship between Electrical Energy Consumption and Climate Factors in Lebanon: On-Integration and Error-Correction Models. International Journal of Energy Research, 25, 1033-1042. https://doi.org/10.1002/er.735

[16] Parkpoom, S., Harrison, G.P. and Bialek, J.W. (2004) Climate Change Impacts on Electricity Demand. In: Nouri, H., Ed., Proceedings of the 39 th International Universities Power Engineering Conference, Bristol, Section T14.2.

[17] Correlation and Covariance. http://onlinestatbook.com/2/describing_bivariate_data/pearson.html 


\section{Annexure}

- The $p$-value is defined informally as the probability of obtaining a result equal to or "more extreme" than what was actually observed, when the null hypothesis is true.

- R-squared is a statistical measure of how close the data are to the fitted regression line. It is also known as the coefficient of determination and R-squared = Explained variation/Total variation .

- The diagonal of a covariance matrix provides the variance of each individual variable: covariance with itself and the off-diagonal entries in the matrix provide the covariance between each variable pair. The positive value determines positive relation between two variables and vice versa. 